\title{
EDITORIAL
}

\section{In This Issue: From Apprehension to Action}

Robin S. Gotler, MA, Reflections Editor

Kurt C. Stange, $M D, P b D$, Editor

Ann Fam Med 2011;9:386-387. doi:10.1370/afm.1252

$\mathrm{T}$ hirty years ago, Ian McWhinney described "the importance of the physician in...mobilizing the patient's inner resources and working with him as a partner in the healing process."1 This concept of a trusting patient-physician partnership has long been an ideal of family medicine and primary care. In this issue of the Annals, several articles shed light on the state of the healing partnership.

\section{APPREHENSIONS AND APPROACHES}

By now, it's well known that patients are often apprehensive about revealing the use of complementary and alternative medicine (CAM) to their clinicians. Hsu and colleagues posit that incorporating CAM therapies into primary care practice may, among other benefits, eliminate the need for such fear, and they find that both patients and clinicians are open to this possibility. ${ }^{2}$ Depression is another topic that patients are hesitant to raise. In a population-based study by Bell et al ${ }^{3}$ more than two-fifths of respondents held beliefs that could inhibit disclosure of depression symptoms to their primary care physician, including, most commonly, a concern that the physician will prescribe antidepressants.

Both studies recognize patient-physician dialogue as a key element for addressing patients' apprehensions. Epstein and Street offer a thought-provoking approach to one aspect of this complex interaction: shared decision making. ${ }^{4}$ They introduce the concept of shared mind, a deliberative process involving patient, clinician, and family that could ultimately strengthen a patient's decision-making process and autonomy.

\section{COUNSELING FOR HEALTHY BEHAVIORS}

The crucial task of helping patients adopt healthy behaviors requires both partnership and strategy. Two articles offer new insights into the potential of primary care visits in particular for tailored health behavior counseling. ${ }^{5-10}$ Cohen and colleagues find that combining health risk assessment and counseling is both fea- sible and effective, ${ }^{11}$ whereas Carroll et al provide an important new tool to assess the use and effectiveness of the 5As (ask, advise, assess, assist, arrange), a strategy for brief physical activity counseling. ${ }^{12,13}$

\section{THE BENEFITS AND BURDENS OF EHRS}

Depending on whom you ask, the electronic health record (EHR) has brought benefits, burdens, bewilderment, or some combination of the above to the primary care setting. Two articles in this issue demonstrate the promise, as well as some of the realities, of EHRs. Koopman et al find that, in a proprietary EHR, information for managing diabetes patients is easier to find when it is summarized on a dedicated dashboard screen. ${ }^{14}$ Another electronic tool, e-prescribing, has been touted for its potential to improve quality, efficiency, and cost, but a study by Crosson et al finds that implementation of e-prescribing is not without costs of its own: successful adoption of e-prescribing takes substantial planning and a willingness to transform work processes..$^{15}$

An editorial by Jaén provides important context for these articles. ${ }^{16}$ EHRs, he reminds us, are designed for documentation and billing purposes, rather than for clinical operations and ongoing chronic illness care. If they are to facilitate, not hinder, primary care practice, we must bring together technical expertise with clinical relevance while committing to truly understanding and opening to the changes that EHRs will engender. An editorial by Sittig and Ash applies an 8-point model for the use of health information technology. ${ }^{17}$

\section{CORONARY RISK AND RISKY MEDICATION USE}

A study evaluating 2 coronary disease risk-scoring mechanisms in a primary care population finds that the original Framingham score overestimates risk whereas the REGICOR version underestimates it. ${ }^{18}$ The original Framingham score targets approximately twice as many 
people for lipid- and blood pressure-lowering therapy than the REGICOR version.

In the US population, nonsteroidal anti-inflammatory drugs (NSAIDs) are used at low rates but are twice as likely to be used by people with moderate to severe kidney disease. ${ }^{19}$ Given that NSAIDs are available without a prescription, and that $10 \%$ of users have a prescription, patients with kidney disease and their clinicians face a balancing act between the potentially detrimental effects of these medications on kidney function and the comorbid conditions they are treating. The study calls for consideration of safer alternatives.

Please join in the discussion of articles at http:// www.AnnFamMed.org.

\section{References}

1. McWhinney lan R. An Introduction to Family Medicine. New York, NY: Oxford University Press; 1981:57

2. Hsu C, Cherkin DC, Hoffmeyer S, Sherman KJ, Phillips WR. Patient and clinician openness to including a broader range of healing options in primary care. Ann Fam Med. 2011;9(5):447-453.

3. Bell RA, Franks P, Duberstein PR, et al. Suffering in silence: reasons for not disclosing depression in primary care. Ann Fam Med. 2011;9(5):439-446.

4. Epstein RM, Street RL Jr. Shared mind: communication, decisionmaking, and autonomy in serious illness. Ann Fam Med. 2011;9(5): 454-461.

5. Balasubramanian BA, Cohen DJ, Clark EC, et al. Practice-level approaches for behavioral counseling and patient health behaviors. Am J Pre Med. 2008;35(5 Suppl):S407-S413.

6. Cohen DJ, Tallia AF, Crabtree BF, Young DM. Implementing health behavior change in primary care: lessons from prescription for health. Ann Fam Med. 2005;3(Suppl 2):S12-S19.

7. Glanz K, Rimer BK, Viswanath K. Health Behavior and Health Education: Theory, Research, and Practice. 4th ed. New York, NY: John Wiley and Sons; 2008.
8. Glasgow RE, Klesges LM, Dzewaltowski DA, Bull SS, Estabrooks P. The future of health behavior change research: what is needed to improve translation of research into health promotion practice? Ann Behav Med. 2004;27(1):3-12

9. Lawson PJ, Flocke SA. Teachable moments for health behavior change: a concept analysis. Patient Educ Couns. 2009;76(1):25-30.

10. Ruffin MT, Nease DE Jr, Sen A, et al. Effect of preventive messages tailored to family history on health behaviors: the Family Healthware Impact Trial. Ann Fam Med. 2011;9(1):3-11.

11. Cohen DJ, Balasubramanian BA, Isaacson NF, Clark EC, Etz RS, Crabtree BF. Coordination of health behavior counseling in primary care. Ann Fam Med. 2011;9(5):406-415.

12. Whitlock EP, Orleans $C T$, Pender N, Allan J. Evaluating primary care behavioral counseling interventions: an evidence-based approach. Am J Prev Med. 2002;22(4):267-284.

13. Carroll JK, Antognoli E, Flocke SA. Evaluation of physical activity counseling in primary care using direct observation of the 5As. Ann Fam Med. 2011;9(5):416-422.

14. Koopman RJ, Kochendorfer KM, Moore JL, et al. A diabetes dashboard and physician efficiency and accuracy in accessing data needed for high-quality diabetes care. Ann Fam Med. 2011;9(5): 398-405.

15. Crosson JC, Etz RS, Wu S, Strauss SG, Eisenman D, Bell DS. Meaningful use of electronic prescribing in 5 exemplar primary care practices. Ann Fam Med. 2011;9(5):392-397.

16. Jaén CR. Successful health information technology implementation requires practice and health care system transformation. Ann Fam Med. 2011;9(5):388-389.

17. Sittig DF, Ash JS. On the importance of using a multidimensional sociotechnical model to study health information technology. Ann Fam Med. 2011;9(5):390-391.

18. Buitrago F, Calvo-Hueros Jl, Cañón-Barroso L, et al. Original and REGICOR Framingham functions in a nondiabetic population of a Spanish health-care center: a validation study. Ann Fam Med. 2011;9(5):431-438.

19. Plantinga L, Grubbs V, Sarkar U, et al. Nonsteroidal anti-inflammatory drug use among persons with chronic kidney disease in the United States. Ann Fam Med. 2011;9(5):423-430. 